\title{
Blindness: Indian scenario: Is it really preventable?
}

\author{
Iqbal S ${ }^{1}$, Dubey AK ${ }^{2}$, Gedam $\mathrm{DS}^{3}$ \\ ${ }^{1}$ Dr S Iqbal, Professor of Anatomy, Amala Institute of Medical Sciences, Amala Nagar, Thrissur, Kerala, India, ${ }^{2}$ Dr Arvind \\ Kumar Dubey*, Professor of Opthalmology, ${ }^{3}$ Dr D Sharad Gedam*, Associate Professor of Pediatrics, *Affiliated with L N \\ Medical College, Bhopal, India.
}

Address for Correspondence: Dr S Iqbal, Email: dr.iqbal.s@gmail.com

\begin{abstract}
Blindness \& visual impairment are important preventable morbidities. It is more important in developing countries like India. Two important aspects are lack of medical care available in peripheral part of country \& lack of awareness of general population for medical care. Almost $80-90 \%$ of population is suffering from preventable cause of blindness. There is an urgent need for screening programs \& availability of medical care from government \& Non government organization in our country.
\end{abstract}

Key words: Blindness, Indian scenario, preventable cause

\section{Introduction}

Visual impairment is a significant health problem affecting the common man worldwide. The World Health Organization (WHO) estimates, between 300 million and 400 million people are visually impaired due to various causes. Of this group, approximately 50 million people are totally blind. Eighty percent of blindness occurs in people over 50 years old. It has been estimated that over $80 \%-90 \%$ of global blindness is preventable through a combination of good medical care and education. Blindness affects all nations, most vicious in the developing world, due to associated poverty and ignorance, and is most commonly found in rural, often remote and under developed areas in as well as in the urban slums ${ }^{1 .}$

The major causes of blindness include cataract, uncorrected refractive errors, glaucoma, macular degeneration, corneal opacities due to trauma and infections, diabetic retinopathy, trachoma and onchocerciasis. Less common causes include vitamin A deficiency, retinopathy of prematurity, vascular disease affecting retina or optic nerve, ocular inflammatory disease, retinitis pigmentosa, primary or secondary malignancies of the eye, congenital abnormalities, hereditary diseases of the eye, and chemical poisoning from toxic agents such as methanol ${ }^{2}$.
Blindness is strictly defined as the state of being totally sightless in both eyes. A completely blind individual is unable to see all. The term blindness, however, is commonly used to signify visual impairment, or low vision, meaning that even with eye glasses, contact lenses, medicine or surgery, a person does not see well. Vision impairment can range from mild to severe. Legal blindness is defined by lawmakers in nations or states in order to either limit allowable activities, such as driving, or to provide preferential governmental benefits, in the form of educational, service or monetary assistance ${ }^{3}$.

\section{Global Scenario}

Every year 1-2 million people go blind. One person goes blind in every 5 seconds and one child goes blind in every minute. The global data bank on blindness maintained by WHO (prevention of blindness division), states that based on 2002 population, a reduction in the number of persons who are blind, visually impaired and those blind due to infectious diseases, but an increase in number of people who are blind from condition related to longer life span. Based on 2002 population, about 161 million people were visually impaired of whom 124 million had low vision and 37 million were blind, however refractive errors as a cause of visual impairment was not included which implies that actual burden is greater. Based on $2006 \mathrm{WHO}$

Available online at: www.ijmrr.in 255 | P a g e


statistics, 314 million people are visually impaired, out of which 45 million are blind and this included visual impairment due to uncorrected refractive errors 4,5 .

Worldwide for each blind person an average of 3.4 people have low vision with country and regional variation vary from $2.4-5.5$. Of the total blind in the world more than $2 / 3^{\text {rds }}$ are living in Asia and Africa. The developed countries like, Europe, America \& Japan have three blind for 1000 population, where in Asia 9 blind and in Africa 12 blind per 1000 population. In other words, the developing countries have 3-4 times higher blindness compared to developed countries and nine out of ten of the world's blind live in a developing country ${ }^{6 .}$ The geographical distribution of global blindness is depicted in Fig - 1.7 .

Cataract $(47.8 \%)$ continues to be a major cause for global blindness, especially in the developing countries. Glaucoma (12.3\%), age-related macular degeneration $(8.7 \%)$ and diabetic retinopathy $(4.8 \%)$, along with cataract, account for close to $75 \%$ of all blindness in the world.

Taking into account the changes in world population over the past 12 years, the magnitude of blindness in 2002 appears to be lower than was projected - 37 million, instead of the projected 52 million. These figures seem to indicate early success for VISION 2020, but also continue to highlight the challenge of achieving the VISION 2020 goal of eliminating avoidable blindness ${ }^{8,9}$.

In spite of considerable efforts in many developing countries, through their national blindness prevention programs, the global number of blind and visually disabled seems to be on the rise, mainly as an effect of population increase and ageing. Without proper interventions 76 million people could be blind by year 2020 . Yet $75 \%$ of blindness is avoidable.

Avoidable Blindness, defined as blindness which could be either treated or prevented by known, cost-effective methods. VISION 2020 seeks to address the main causes of avoidable blindness viz., cataract, trachoma, onchocerciasis, childhood blindness, refractive error, low vision glaucoma and diabetic retinopathy, in order to have the greatest possible impact on vision loss worldwide.

This Global Initiative addresses the issue in terms of (i) disease control; (ii) human resource development; and (iii) infrastructure strengthening and appropriate technology development for eye care delivery ${ }^{10}$.

\section{Indian scenario}

India, world's second largest population, has the distinction of being the home of the world's largest number of blind people. World Health Organization (WHO) statistics revealed that approximately 63 million people in India are visually impaired, and of these 8 million people are totally blind. The number of blind persons in India in 2000 was estimated to be 18.7 million. The projected number of blind persons in India would increase to 24.1 million in 2010 and 31.6 million $2020^{11 .}$

Based on Government of India statistics (2011), one out of every three blind persons in the world lives in India. Over 15 million people are blind out of which 11.75 million live in the rural and most backward areas. Over 9.4 million have cataract related blindness. 2.8 million are blind due to refractive error. 6 million people become blind with low vision every year. 3.2 million children are blind under the age of 16 years, Only $5 \%$ of them receive any education. 12 million people could be saved from become blind 9 .

Cataract is the leading cause of blindness in India while refractive error and glaucoma are the second and third leading causes of blindness respectively. Since trachoma is limited, onchocerciasis is non-existent; glaucoma, diabetic retinopathy and corneal diseases along with cataract and refractive errors - form priorities under India's vision 2020 action plan ${ }^{12}$.

About $75-80 \%$ of these are cases of avoidable blindness, thanks to the country's acute shortage of trained manpower and lack of donated eyes for the treatment of corneal transplants. India needs 2.5 lakh donated eyes every year, but the country's 109 eye banks manage to collect a maximum of just 25,000 eyes, $30 \%$ of which can't be used.

So the shortage of donated eyes is becoming a huge problem. Of the 15 million blind people in India, three million, (26\%) of whom are children, suffer due to corneal disorders. But only 10,000 corneal transplants are being done every year due to the shortage of donated eyes.

The Union health ministry has already launched a national programme to control blindness and expects to reach its blindness elimination target of $0.3 \%$ by 2015 , five years before the WHO deadline of $2020{ }^{13}$. The various causes of blindness in India and the age distribution are given in Figure 2 and $3^{11,12}$. 


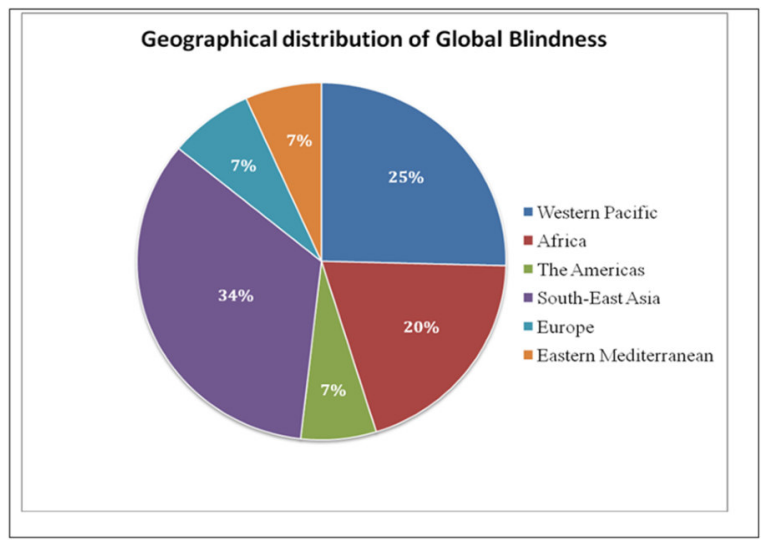

Fig 1: Geographical distribution of Global Blindness

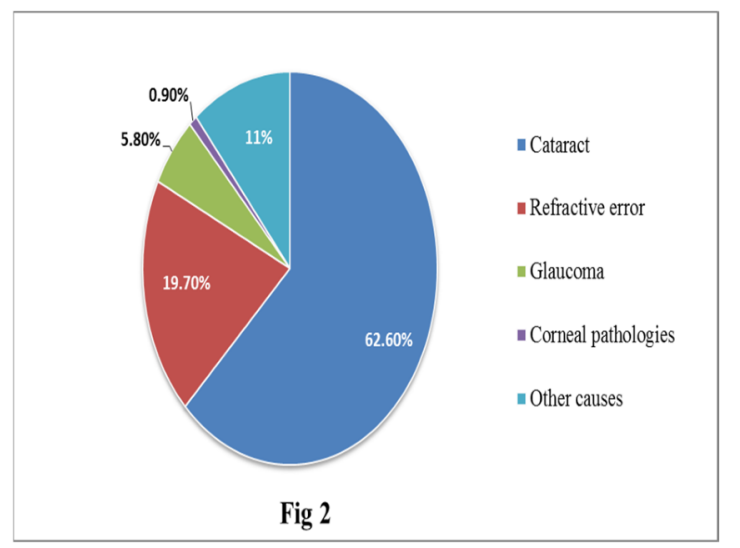

Fig 2: Causes of Blindness in India
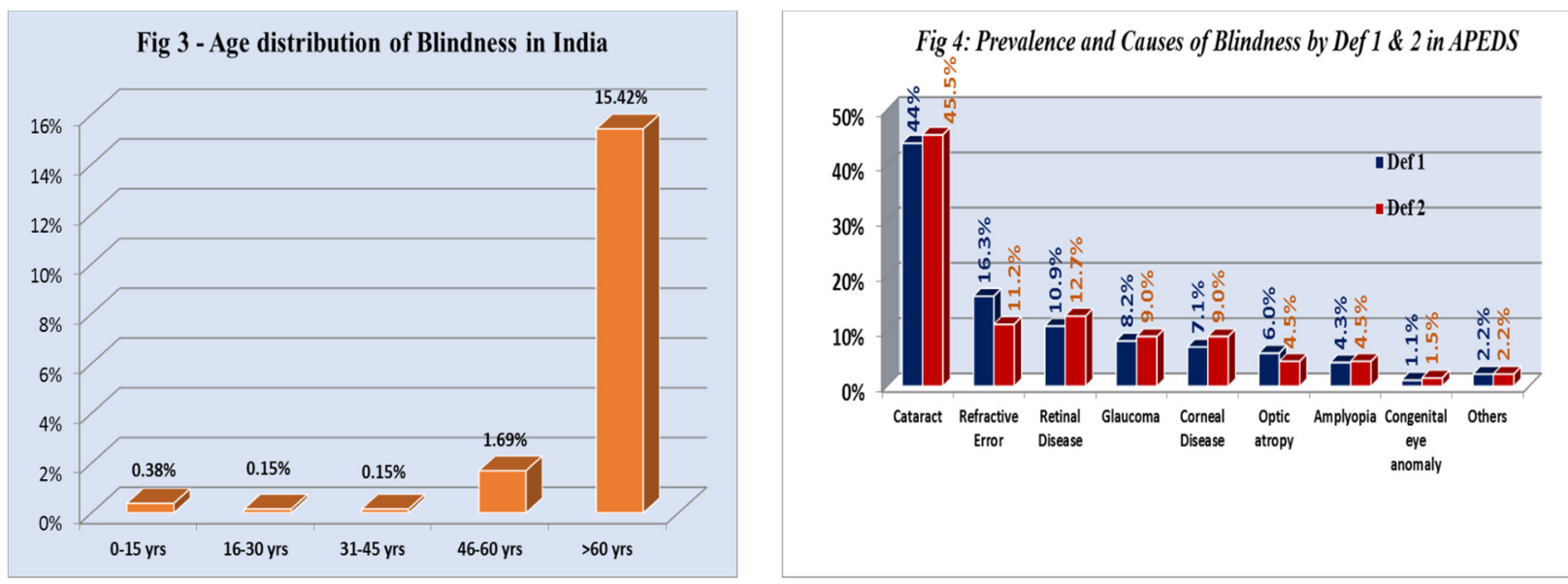

Fig 3: Age distribution of Blindness in India

Fig 4: Prevalence and Causes of Blindness by Def 1 and Def 2 in APEDS

Childhood blindness is a public health problem in developing countries inhabiting $75 \%$ of the world's blind children. Therefore, childhood blindness is given the top priority of "Vision 2020 - the Right to Sight," document to eliminate this avoidable blindness. The prevalence range is from $3 / 10000$ in children of affluent societies to $15 / 10000$ in the poorest communities. In India 3,20,000 children below 16 years are blind, and this constitutes $1 / 5$ of the world's blind children population ${ }^{14}$. According to Dandona et al., ${ }^{15}$ the prevalence of blindness was $0.17 \%$. which corresponds to $6,80,000$ children, after extrapolation. Corneal opacities due to Vitamin A deficiency (Vit. A), measles and trauma, is the common cause of childhood blindness.

Childhood Cataract accounted for 39\% of blindness, followed by Trachoma and Glaucoma ${ }^{16 .}$ Vit. A deficiency is the cause of blindness in $24 \%$ of children in blind schools of North Eastern States of India ${ }^{17}$. At present the prevalence of Vit. A deficiency has been on the decline, which may be due to vitamin A supplementation and measles immunization. Even though the incidence of clinical Vit. A deficiency in India has declined significantly; India still has a relatively highest percentage of Vitamin A deficient children in the world. It persists as a public health problem, mainly in rural and remote areas. So childhood blindness has become a concern for the society, because of many years of visual impairment in front of them. Control of vitamin A deficiency is covered under the Reproductive and Child Health Program in India. The coverage of prophylactic vitamin A administration along with immunization in India has been reported to be poor.

This has to be improved through better primary health care, along with efforts to improve awareness about and intake of vitamin A rich foods viz., leafy vegetables, milk and egg which are natural sources of Vitamin A ${ }^{18}$ At present the childhood blindness in India is of like the middle income group countries with congenital anomalies, premature retinopathy, and cataract being the common causes, but vitamin A deficiency, infection, and trauma are still continued to be prime causes in remote regions of the country, including north-eastern states ${ }^{17}$. 
Review Article

India was the first country to launch a National Program for the Control of Blindness in year 1976. Various population based surveys among older populations have shown that cataract is the predominant cause of avoidable blindness in India. The emphasis on cataract surgery was given top priority in the national blindness control program. The Government of India in association with World Health Organization started the cataract surgery program with the assistance of World Bank to combat this avoidable blindness. This project produced a paradigm shift in surgical techniques, which resulted in dramatic changes both in the quantum and technology for cataract surgery.

The annual number of cataract surgeries in India also increased from 1.2 million in 1990 to 4.8 million in 2006 . There is also a demand from general population for an advanced intraocular lens implant (IOL) for better visual outcomes. In the present context over $99 \%$ of all cataract surgeries in India were performed using advanced intra ocular lens implant. One of the national goals to prevent avoidable blindness was to reduce prevalence of blindness from $1.4 \%$ to $0.3 \%$ by the year 2000 . With better public, private and NGO coordination, India's cataract surgery figures rose dramatically from about a million in the early 1990s to more than 6 million by $2010^{19,20 .}$

The Andhra Pradesh Eye Disease Study (APEDS) with its meticulous and comprehensive approach demonstrated that almost $50 \%$ of blindness was due to causes other than cataract.

This includes refractive error, retinal diseases, glaucoma, corneal disease, optic atrophy, amblyopia, congenital eye anomaly and others. The prevalence and causes of blindness in APEDS Study using two definitions for blindness (def 1 - Visual acuity $<6 / 60$ and def 2 - Visual acuity $<3 / 60$ ) were enumerated in Fig $4^{21,22,23 .}$

Refractive error-related blindness accounts for more than twice the number of blind-person-years compared with cataract over the lifetime because blindness due to refractive error manifests at a young age. Over $60 \%$ of this blindness was due to myopia, with hypermetropia and amblyopia accounts for the remaining. This preventable blindness can be addressed if adequate refractive services are available for early detection with appropriate correction of refractive error. Also there is a need to develop systems through which the poor can obtain spectacles at an affordable price $23,24,25$.

Corneal blindness is one of the most common causes of blindness in India. India shoulders the largest burden of global blindness, about 3.5 million across the country with 30000 new cases being added each year. At present approximately 35,000 corneas are collected in the country every year, whereas 150,000 are required annually to combat corneal blindness. As a result, the patient line-up and wait to get a corneal transplant keeps getting longer with each passing day. Furthermore, the cost of cornea transplant in addition to unavailability for corneas makes it practically impossible for underprivileged society to access these medical remedies. Creating awareness amongst the masses and encouraging them to pledge their eyes for donation, therefore, is of paramount importance 26. Blindness due to primary angle-closure glaucoma is potentially avoidable if this condition is detected early and peripheral iridotomy or iridectomy is performed.

Blindness due to primary open-angle glaucoma is more difficult to prevent, and less than $50 \%$ of this may be preventable if this condition is detected early with good optic disc examination and applanation tonometry. Because the examination techniques required to detect glaucoma early are not practiced commonly in India, better training of eye care providers in India has to be initiated, if blindness due to glaucoma has to be prevented. ${ }^{27,28 .}$

Diabetes is a major cause of morbidity worldwide and is becoming a leading contributor to preventable blindness. Previous studies had shown that diabetic retinopathy cause less than $1 \%$ of blindness, but recent surveys reveal it as an emerging cause of blindness rapidly ascending in the chart of causes of avoidable blindness in India and worldwide. Diabetic retinopathy is caused by damage to micro-vascular system in the retina due to prolonged hyperglycaemia.

The CURES Eye study showed that the major risk factors for onset and progression of Diabetic retinopathy were duration of diabetes, degree of glycemic control and hyperlipidaemia. In India with the epidemic increase in Type 2 Diabetes mellitus (WHO), Diabetic retinopathy is fast becoming an important cause of visual disability. The visual impairment from Diabetes is a significant public health problem; however this morbidity is largely preventable and treatable. If managed with timely intervention, the quality of life can be preserved ${ }^{29,30,31}$.

The Rapid Assessment of Avoidable Blindness in India (RAAB) revealed refractive errors, cataract, surgical complications, aphakia, trachoma, diabetic retinopathy, glaucoma and corneal opacity as a major cause of blindness and low vision in India. About $91.8 \%$ of these blindness were seen in patients over 50 years and is preventable. This prevalence is higher than what has been reported in most other countries. This is again due to the high incidence of cataract blindness in India. Evidence 
suggests that over the next decade if cataract surgical services and refraction services are augmented both in quantity and quality, the country would be well prepared to eliminate avoidable blindness by 2020 . If this does not happen, then the likelihood of achieving the goals of Vision 2020: The Right to Sight initiative would remain a dream that would take till eternity to be translated into reality ${ }^{32}$. Despite the recent economic boom, the divide between the rich and poor continues to increase, leaving a significant portion of the population without access to basic health care services - most of whom live either in rural India or in urban slums. So India needs a holistic, sincere and comprehensive approach to tackle the avoidable blindness starting from patients' education itself.

India has been able to arrest the increasing prevalence of blindness by meticulous planning and careful implementation of the blindness control programs with healthy partnership between government, nongovernmental organizations, and private sectors being forged to deliver results. Part of the change in prevalence would also have happened because of secular trends, better availability of services, improved socioeconomic status, etc, and together with a focused programme, the cumulative benefit may be much higher. The Vision 2020 has set laudable goals for blindness amelioration.

Ophthalmologists and other primary eye care practitioners need to gear up to this challenge. The vision center approach with a pyramidal shaped health care system can focus as an equitable and comprehensive eye care approach to tackle all causes of blindness and visual impairment 33. Once our eye banking system is well established and cataract surgery outcomes further improve, the present Indian scenario changes abruptly with retinal and optic nerve disorders as the major causes of blindness in future as in the developed world.

\section{Conflicts of Interest: Nil.}

Acknowledgement: Author thanks Dr Ajith TA, Professor of Biochemistry and Miss Rejitha K, Statistician of Amala Institute of Medical sciences, Thrissur, Kerala for their valuable help in preparation of this manuscript.

\section{References}

1. Source: Andrew A. Dahl, MD, FACS, MedicineNet.com.

2. Source: NIH Medicine Plus; Summer 2008 Issue: Volume 3 Number 3 Pages 14 - 15.
3. Visual impairment and blindness. World Health Organization; June 2012.

4. Resnikoff S, Pascolini D, Etya'ale D, Kocur I, Pararajasegaram R, Pokharel GP, Mariotti SP. Global data on visual impairment in the year 2002. Bull World Health Organ. 2004 Nov;82(11):844-51

5. Source: Global data on visual impairments, 2010 (www.Who.int)

6. Anuja U. Blindness - Current scenario. Department of Community Medicine, Medical College, Trivandrum (WWW.Commedtvm.org).

\section{Source: www.cureblindness.org}

8. Roodhooft JMJ. Leading Causes of Blindness Worldwide. Bull Soc Belge Ophthalmol. 2002; 283: 1925.

9. Source: Blindness - Global and Indian scenario. Anugraha Drishtidaan (WHO-2010; Govt. of India2011).

10. Source: Vision 2020 doc. WHO (IAPB) Global action plan 2014-19.

11. Sagar Borker. Epidemiological study of prevalence and causes of visual disability in a rural community. $J$. Indian Academy of Geriatrics. 2011; 7: 1-5.

\section{Source: www.vision2020india.org}

13. Source: The Times of India-Oct 11, 2007.

14. Murthy GV, Gupta SK, Ellwein LB, Muñoz SR, Pokharel GP, Sanga L, Bachani D. Refractive error in children in an urban population in New Delhi. Invest Ophthalmol Vis Sci. 2002 Mar;43(3):623-31

15. Dandona R, Dandona L, Srinivas $\mathrm{M}$, Sahare P, Narsaiah S, Muñoz SR, Pokharel GP, Ellwein LB.. Refractive error in children in a rural population in India. Invest Ophthalmol Vis Sci. 2002 Mar;43(3):615-22.

16. Source: Orbis - 2010; www.orbis.org

17. Bhattacharjee H, Das K, Borah RR, Guha K, Gogate P, Purukayastha S, Gilbert C. Causes of childhood blindness in north eastern states of India. Indian $\mathrm{J}$ Ophthalmol. 2008 Nov-Dec;56(6):495-9

18. United Nations Children Fund. The State of the World's Children 2000. New York: UNICEF; 2000.

19. Pararajasegaram R. Vision 2020- The Right to Sight: From strategies to action. Am J Ophthalmol 1999;128:359-60.

Available online at: $\underline{w w w . i j m r r . i n}$

259 | P a g e 
20. Murthy G, Gupta SK, John N, Vashist P. Current status of cataract blindness and Vision 2020: The right to sight initiative in India.IndianJOphthalmol2008;56:489-94

21. Dandona L, Dandona R, Srinivas M, Giridhar P, Vilas K, Prasad MN, John RK, McCarty CA, Rao GN.. Blindness in the Indian State of Andhra Pradesh. Investigative Ophthalmology and Visual Science. 2001; 42 (5): 908-916

22. Dandona L, Dandona R, Naduvilath TJ, McCarty CA, Nanda A, Srinivas M, Mandal P, Rao GN.. Is current eye care policy focus almost exclusively on cataract adequate to deal with blindness in India. Lancet. 1998 May 2;351(9112):1312-6.

23. Dandona L, Dandona R, Shamanna BR, Rao GN. A model for high-quality sustainable eye-care services in rural India. In: Pararajasegaram R, Rao GN, eds. World Blindness and Its Prevention. Volume 6. Hyderabad: International Agency for the Prevention of Blindness; 2001 .

24. Dandona R, Dandona L, Srinivas M, Sahare P, Narsaiah S, Muñoz SR, Pokharel GP, Ellwein LB. Refractive error in children in a rural population in India. Invest Ophthalmol Vis Sci. 2002 Mar;43(3):615-22

25. Murthy GV, Gupta SK, Ellwein LB, Muñoz SR, Pokharel GP, Sanga L, Bachani D. Refractive error in children in an urban population in New Delhi. Invest Ophthalmol Vis Sci. 2002 Mar;43(3):623-31.

26. Source: www.netradaan.com
27. Gogate P, Deshpande R, Chelerkar V, Deshpande S, Deshpande M. Is glaucoma blindness a disease of deprivation and ignorance? A case control study for late presentation of glaucoma in India. Indian J Ophthalmol 2011;59:29-35.

28. Dandona L, Dandona R,Mandal P, Srinivas M, John RK, MacCarty CA, Rao GN. Angle Closure glaucoma in an urban population in southern India: the Andhra Pradesh Eye Disease Study. Ophthalmology. 2000;107(9):17101716.

29. Agarwal S, Raman R, Paul PG, Rani PK, Uthra S, Gayathree R, McCarty C, Kumaramanickavel G, Sharma T.Ophthalmic Epidemiol. 2005 Apr;12(2):143-53.

30. Yau JW, Rogers SL, Kawasaki R, Lamoureux EL, Kowalski JW, Bek T, et al. Global prevalence and major risk factors of diabetic retinopathy. Diabetes Care. 2012 Mar;35(3):556-64.

31. Rema M, Pradeepa R. Diabetic retinopathy: An Indian perspective. Indian J Med Res. 2007; 125: 297-310.

32. Neena J, Rachel J, Praveen V, Murthy GV. Rapid Assessment of Avoidable Blindness India Study Group. Rapid assessment of avoidable blindness in India. PLoS One 2008;3:e2867.

33. Rao GN. An infrastructure model for the implementation of Vision 2020: The right to sight. Can J Ophthalmol 2004;39:589-94.

\section{How to cite this article?}

Iqbal S, Dubey AK, Gedam DS. Blindness: Indian scenario: Is it really preventable? Int J Med Res Rev 2013;1(5):255-260. doi:10.17511/ijmrr.2013.i05.11. 